\title{
Nonverbal Reactions to an Attractive Stranger: The Role of Mimicry in Communicating Preferred Social Distance
}

Article in Journal of Nonverbal Behavior · June 2014

DOI: 10.1007/s10919-014-0174-4

CITATIONS

READS

8

376

1 author:

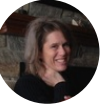

Sally D Farley

University of Baltimore

18 PUBLICATIONS 157 CITATIONS

SEE PROFILE

Some of the authors of this publication are also working on these related projects:

Project

Are nonverbal engagement signals or self-reported attitudes better predictors of behavior? View project 


\section{Nonverbal Reactions to an Attractive}

\section{Stranger: The Role of Mimicry in}

\section{Communicating Preferred Social Distance}

\section{Sally D. Farley}

\section{Journal of Nonverbal Behavior}

ISSN 0191-5886

Volume 38

Number 2

J Nonverbal Behav (2014) 38:195-208 DOI 10.1007/s10919-014-0174-4

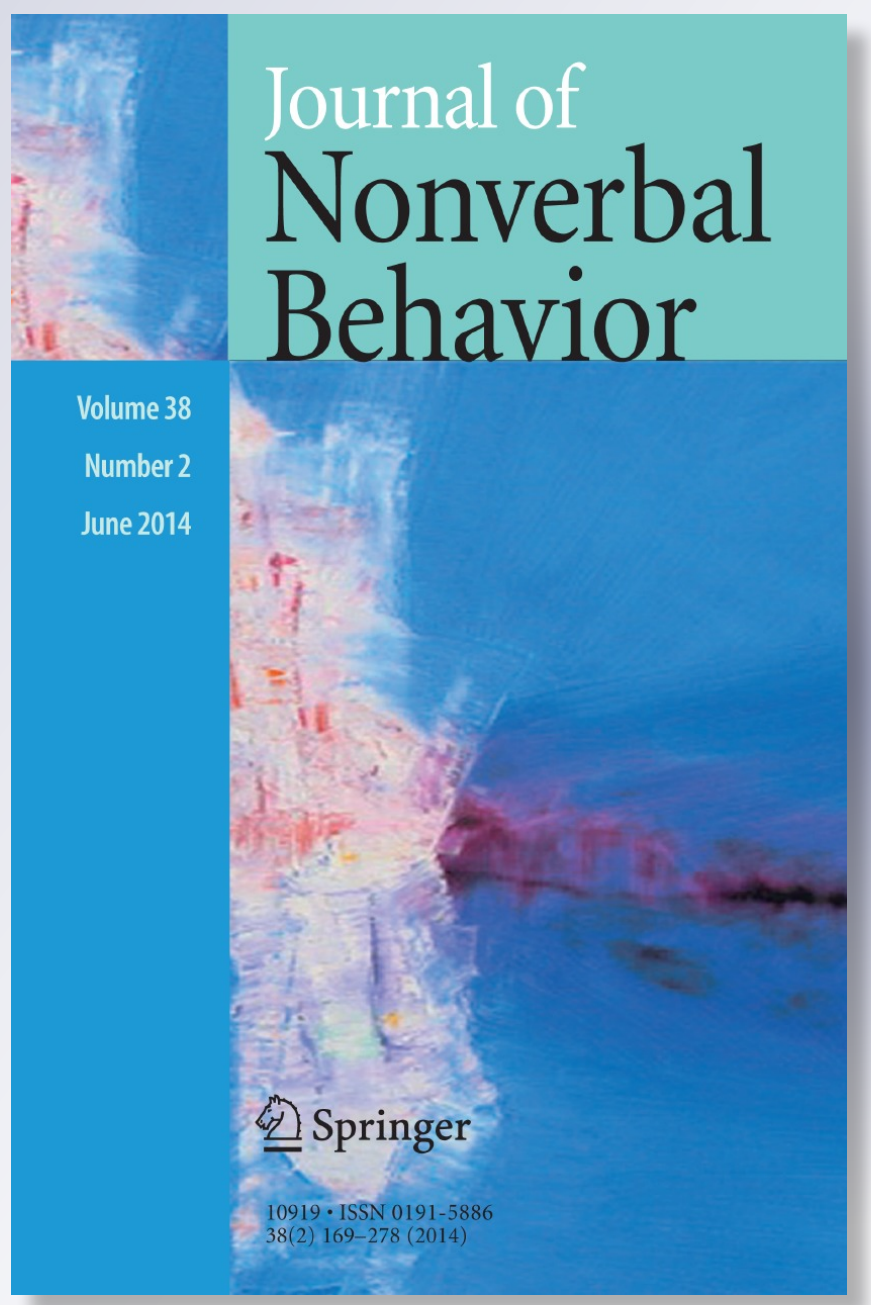

Springer 
Your article is protected by copyright and all rights are held exclusively by Springer Science +Business Media New York. This e-offprint is for personal use only and shall not be selfarchived in electronic repositories. If you wish to self-archive your article, please use the accepted manuscript version for posting on your own website. You may further deposit the accepted manuscript version in any repository, provided it is only made publicly available 12 months after official publication or later and provided acknowledgement is given to the original source of publication and a link is inserted to the published article on Springer's website. The link must be accompanied by the following text: "The final publication is available at link.springer.com". 


\title{
Nonverbal Reactions to an Attractive Stranger: The Role of Mimicry in Communicating Preferred Social Distance
}

\author{
Sally D. Farley
}

Published online: 12 January 2014

(C) Springer Science+Business Media New York 2014

\begin{abstract}
The present study was conducted to determine the extent to which different nonverbal behaviors were associated with romantic interest in a highly attractive confederate and whether these behaviors differed as a function of relationship status and selfreported love for one's partner. Mimicry was positively associated with romantic interest in the confederate, and consistent with the devaluation hypothesis, mimicry was negatively associated with self-reported love for one's partner, suggesting that mimicry functions to signal preferred social distance. In addition, smiling and vocal pleasantness emerged as important affiliative nonverbal behaviors. The present results suggest that mimicry acts as a relationship-maintenance mechanism, one that is expressed automatically, unintentionally, and nonconsciously. Implications for the role of nonconscious mimicry in romantic attraction and relationship-maintenance processes are discussed.
\end{abstract}

Keywords Mimicry · Relationship-maintenance · Nonverbal · Love · Romantic interest

\section{Introduction}

Early stage romantic love is dizzyingly intoxicating. Young lovers have an insatiable desire for affection from their partners, experience intrusive thoughts about their loved ones, and express great distress at the prospect of losing them (Fisher 1998; Hatfield and Rapson 1993). According to biological anthropologist Helen Fisher (1998), romantic love is a fundamental drive, motivating us to focus intense energy on a single person; science supports George Bernard Shaw's notion that "love is a gross exaggeration of the difference between one person and everybody else" (as cited in Murray et al. 1996, p. 88). Although the flame of romantic love burns less brightly over time, as its physiological intensity diminishes, passion, commitment, and intimacy remain central components of love (Johnson and Rusbult 1989; Sternberg 1986).

S. D. Farley $(\bowtie)$

Division of Applied Behavioral Sciences, University of Baltimore, Baltimore, MD 21201, USA

e-mail: sfarley@ubalt.edu 
According to evolutionary theory, romantic love may have evolved as a psychological mechanism in order to promote long-term pair-bonding and relational commitment (Maner et al. 2008). Commitment has been implicated as an especially important predictor of relationship-maintenance behaviors (Johnson and Rusbult 1989). Highly committed individuals experience a positivity bias in their romantic relationships, perceiving more positive attributes and fewer negative attributes in their own relationships as compared to others' (Agnew et al. 1998). In addition, an inflated evaluation of one's partner's qualities is associated with relationship happiness (Murray et al. 1996), and longitudinal research indicates that this effect is long-lasting (Murray et al. 2011). Newly married couples with a high positivity bias experienced no significant decrease in marital satisfaction over three years, in comparison to low idealization couples, who experienced a dramatic decrease in relationship satisfaction over time (Murray et al. 2011).

\section{Relationship Maintenance Processes}

Relationship enhancement and protection biases are more pronounced when individuals are confronted with attractive alternatives to their relationship partners. In their seminal article, Johnson and Rusbult (1989) proffered evidence for what has been termed the devaluation or derogation hypothesis, the tendency for highly committed individuals to devalue attractive alternatives in an effort to protect their romantic relationships from threat. In support of the devaluation hypothesis, Miller (1997) found that people who were romantically involved perceived attractive alternatives as less attractive, reported less interest in seeing them again, and experienced less physiological arousal in response to attractive others than did those who were not romantically involved. Attentional processes were likely involved as committed individuals actually spent less time noticing and attending to attractive others (Miller 1997).

Recent research on the devaluation hypothesis has suggested that relationship-protection biases can be experimentally induced (Gonzaga et al. 2006; Maner et al. 2008). Individuals who were assigned to write essays about a time they felt strong feelings of love for their partners showed selective inattention to highly attractive opposite-sex targets (but not highly attractive same-sex targets), suggesting a relationship-protective motivation (Maner et al. 2008). Furthermore, participants assigned to a "love" essay were more successful at suppressing thoughts about an attractive alternative than those assigned to a "sexual desire" condition, leading researchers to conclude that love serves to enhance commitment and decrease temptation (Gonzaga et al. 2006).

Although there is wide support for the tendency for more committed individuals to evaluate attractive alternatives less positively than less committed individuals (see Bazzini and Shaffer 1999; Lydon et al. 2003 for alternative interpretations of the findings), few studies have investigated behavioral reactions to highly attractive alternatives in interaction (see Guéguen 2009; Karremans and Verwijmeren 2008 for exceptions). Given that nonverbal behavior is effective at shaping, maintaining, and reinforcing relationships (Burgoon et al. 2010), nonverbal affiliative cues may combine to act as a mechanism to communicate desired social closeness. Moreover, because nonverbal cues are polysemous, nonconscious, and subtle, individuals may express cues of interest during interactions with attractive alternatives, allowing them to save face in the event that their romantic interest is not reciprocated (i.e., "I was just smiling to be friendly"). Furthermore, cognitive appraisals (e.g., devaluation) of attractive targets should converge with expressed nonverbal behaviors, and both should be predicted by relationship status. 
The purpose of the present experiment was to expose participants-both in and out of relationships - to a highly attractive confederate in order to examine the extent to which different nonverbal cues served as signals of preferred social distance, either preferred closeness or preferred distance. We examined nonconscious mimicry as the primary dependent measure, but a number of other nonverbal behaviors were also analyzed, enabling us to compare their relative importance at predicting romantic interest in the confederate and love for one's partner. The research presented here, which draws from the work and theories of anthropologists, evolutionary psychologists, social psychologists, communication researchers, and relationship scientists is important in that contemporary nonverbal scholarship needs to be more inclusive of the interdisciplinary nature of the field. Furthermore, this research sheds light on a channel of nonverbal communication that has received relatively little empirical attention outside of evolutionary psychology, the vocal channel. While evolutionary psychologists tend to examine the ways in which the vocal channel signals biologically relevant information, the current study examines the situational variability of the voice as a function of attraction and self-reported love.

\section{Mimicry as a Social Distancing Mechanism}

A wealth of literature supports the general tendency for individuals to mimic the gestures, postures, idioms, accents, vocal style, and pitch of their interaction partners (Chartrand and Bargh 1999; Giles 2008; Lakin and Chartrand 2003; McGarva and Warner 2003; Natale 1975). These effects have been termed behavioral coordination (Bernieri and Rosenthal 1991), postural mirroring (LaFrance and Ickes 1981), behavioral matching, interaction synchrony, and vocal convergence (Gregory 1990). Chartrand and Bargh's (1999) pivotal work on the perception-behavior link highlighted the automatic and nonconscious nature of mimicry. Participants in the presence of a foot-shaking confederate were more likely to shake their feet, and participants in the presence of a face-touching confederate were more likely to touch their faces (Chartrand and Bargh 1999; Experiment 1). The recent discovery of mirror neurons (Rizzolatti and Craighero 2004) suggested a neurological mechanism for nonconscious mimicry. However, Moody and McIntosh (2011) found that the emotional content of stimuli influences the tendency to mimic, which is suggestive of the complexity of the underlying mimicry mechanism.

Indeed, results from numerous articles suggest that mimicry is moderated by affiliative interaction goals and motivational states. Mimicry increases perceptions of the smoothness of interaction and increases liking for the mimicker (Chartrand and Bargh 1999, Experiment 2). Mimicry is also associated with self-monitoring and motivation to affiliate (Cheng and Chartrand 2003; Lakin and Chartrand 2003; Lakin et al. 2008). In a relational context, romantically involved individuals mimicked a mannerism of an attractive opposite-sex interaction partner less than those who were not romantically involved (Karremans and Verwijmeren 2008). A rare mimicry field experiment using a speed-dating paradigm found that women who mimicked their partners' gestures and vocal expressions were given higher interest and sexual attractiveness ratings (Guéguen 2009). These findings offer convergent evidence that mimicry functions to communicate desired social distanceincreasing mimicry communicates a desire for greater psychological closeness or affiliation, and decreasing mimicry communicates a desire for distance (or lack of interest). Given that mimicry operates as a "default" in social interactions, in keeping with the perception-behavior link (Chartrand and Bargh 1999), the suppression of mimicry would be especially telling about the relational climate of a dyad's interaction. 
The goals of the present study were to determine the extent to which different nonverbal behaviors were associated with romantic interest in a highly attractive confederate and whether these behaviors differed as a function of relationship status and self-reported love for one's partner. Individuals who are committed to their romantic partners are likely to perceive an attractive alternative as a threat, prompting devaluation processes (Johnson and Rusbult 1989), and, potentially distancing behaviors. Given the role of mimicry in communicating liking, men involved in romantic relationships, especially those reporting greater commitment (Johnson and Rusbult 1989) and love for their partners (Gonzaga et al. 2008) may protect these romantic relationships by engaging in less mimicry of an attractive alternative (Karremans and Verwijmeren 2008).

In the present study, heterosexual men interacted with a highly attractive female confederate who touched her face every $15 \mathrm{~s}$ during a structured interview task. The primary dependent measure was mimicry, the number of times men touched their heads during the interview. A total of 10 additional dependent nonverbal behaviors that have been implicated as connoting attraction, liking, or desire for intimacy were also coded (see below). As part of a "separate study," men answered questions about their relationship status and selfreported feelings of love for their current romantic partner. The post-experimental questionnaire assessed romantic interest in the confederate. Therefore, the present study offered a unique opportunity to triangulate multiple sources of data-self-reported love for one's partner, self-reported interest in an attractive alternative, and nonverbal behaviors-to more accurately assess romantic interest signals.

\section{Affiliative Nonverbal Behaviors}

Historically, nonverbal behaviors have been examined on two dimensions: an involvement, intimacy, or affiliation dimension (Patterson 2006) and a vertical, dominance, or status dimension (Hall et al. 2005). As a result, there is abundant research on the nonverbal behaviors connoting attraction, liking, and desire for intimacy. The affiliative dimension is associated with increases in mimicry (Guéguen 2009), self-touch or automanipulation (Renninger et al. 2004), touching others (Givens 1978), nodding (McCormick and Jones 1989), leaning forward (Koeppel et al. 1993), gesturing, open posture (Renninger et al. 2004), smiling (Floyd and Burgoon 1999), and laughter (Hall et al. 2005). Based upon extensive literature review, Koeppel et al. (1993) wrote that "friendly", "flirty", and "seductive" dyads can be differentiated by their nonverbal behaviors. The more intimate the dyadic relationship, the more smiling, laughter, touching, and eye contact, and the less physical proximity between the parties. Flirting couples also demonstrated some unique behavioral tendencies, such as tilting their heads, pouting their mouths, crossing their legs in the direction of their partners, and glancing toward their partners and then away (Koeppel et al. 1993). After conducting a naturalistic observation of 70 couples in a bar setting, McCormick and Jones (1989) concluded that women more active in the earlier stages of flirtation, signaling their romantic interest through eye contact, smiling, laughing, grooming, and brief touch, while men were more active in the latter stages of flirtation. Because of the importance of these behaviors in communicating romantic attraction, they were coded for the present study.

Moreover, although researchers have speculated about the importance of the vocal channel in communicating romantic interest (Givens 1978; Koeppel et al. 1993), little work has investigated vocal cues systematically. Recent studies have shown that individuals engage in vocal modulation when speaking with attractive others and romantic partners, 
altering their voices so that they sound more pleasant and romantically interested (Farley et al. 2013; Hughes et al. 2010). These findings, coupled with research showing that women's voices are most pleasant-sounding when they are ovulating (Pipitone and Gallup 2008), suggest that vocal pleasantness acts as an availability signal. As a result, one subtle way to distance oneself from a potentially attractive alternative is to decrease the pleasantness of one's voice or alternatively, a way to make oneself more attractive is to increase the pleasantness of one's voice.

\section{Hypotheses}

In light of the literature reviewed, we offer the following hypotheses:

H1 Because mimicry conveys a desire for connectedness, intimacy, and rapport, nonexclusive daters (single men and those involved in their romantic relationships for less than three months, Bazzini and Shaffer 1999) should mimic the confederate more than exclusive daters (those involved in a relationship for more than 3 months). Similarly, non-exclusive daters should show higher rates of affiliative nonverbal behaviors than exclusive daters do.

H2 Mimicry and other affiliative nonverbal behaviors should be positively associated with romantic interest in the confederate.

H3 Furthermore, for men involved in relationships, self-reported love for one's romantic partner should be negatively correlated with mimicry and other affiliative nonverbal behaviors. This should especially be the case for self-reported commitment (Johnson and Rusbult 1989) and passion (Fisher 1998), as opposed to intimacy, due to their role in relationship-maintenance behaviors (Farley et al. 2013).

H4 Devaluation hypothesis: Consistent with the research on devaluation/derogation (Johnson and Rusbult 1989), non-exclusive daters should evaluate the confederate more positively than exclusive daters do.

\section{Method}

\section{Participants}

Initially, participants included 58 heterosexual men. However, five participants were omitted from the data set, two due to previous exposure to the confederate and three due to suspicion of the use of a confederate. Of the remaining 53 participants, 25 were single or involved in a relationship for less than 3 months (non-exclusive daters), 26 were involved in a relationship for more than 3 months (exclusive daters) and 2 had unknown relationship status. The men with unknown relationship status were retained as participants in order to test the romantic interest hypothesis. Statistics revealed that the exclusive and nonexclusive dater groups did not differ in terms of age $[t(45)=-1.67, p=.10]$ or ethnicity $\left[\chi^{2}=.20, p=.56\right]$. Exclusive daters were involved in their relationships for an average of 38.48 months or 3.21 years $(S D=30.36$ months). On average, the men were 25.6 years of age $(S D=5.3)$ and ethnically diverse $(52.8 \%$ Caucasian, $28.3 \%$ African-American, $5.7 \%$ Asian, $1.9 \%$ Hispanic, with $11.3 \%$ failing to report ethnicity). 
Scale Measures

To minimize the extent to which relationship status served as a demand characteristic in the mimicry study, the relationship questions were embedded in an allegedly separate study called the "Personality Study." Participants in the personality study were told that the study concerned the extent to which different personality characteristics were correlated. They answered demographic questions, a question assessing relationship status, and items from Snyder's (1974) self-monitoring scale and Rosenberg's (1965) self-esteem scale as distractors.

The germane measures were self-reported love for one's partner using Hatfield and Rapson's (1993) passionate and companionate love scales. Both scales utilized a 9-point scale ranging from not at all true to definitely true. The passionate love scale, a 15-item scale, captures the physiological intensity of romantic love, including items such as "I would feel deep despair if left me" and "I sense my body responding when touches me" $(\alpha=.89)$. The companionate love scale included a four-item commitment/ decision subscale $(\alpha=.88)$ and a four-item intimacy subscale. Although two items were added to the intimacy subscale in the present study to more explicitly capture self-disclosure and trust [Rubin's (1970) liking item- "I feel that I can confide in this person about virtually everything" and "I trust completely"], the Cronbach's alpha was improved when this final item was omitted $(\alpha=.82)$. A composite love scale created by averaging all three of Sternberg's love components (intimacy, commitment, and passion) was also computed $(\alpha=.92)$.

\section{Experimental Procedure}

The current research project was approved by the Institutional Review Board at the University of Baltimore and conforms to the federal guidelines for the protection of human participants. Participants either received partial credit toward fulfillment of their required research or extra credit in their courses at the University of Baltimore. Participants were recruited for the personality study through an online course management system or in their undergraduate and graduate courses; thus some men completed the study online and some completed it on paper. Heterosexual men were then recruited for the communication study and asked to sign up for that study on a research sign-up board. The average amount of time between completion of the personality study and the communication study was 13.07 days $(S D=10.25)$. A few men $(n=7)$ signed up for the communication study without having taken the personality study, so emails were sent to these individuals asking them to confirm their sexual orientation and relationship status at the time they completed the communication study. Most men $(n=5)$ provided answers to these questions, leaving only two participants with missing data. Men were asked only these two questions, as opposed to the rest of the personality questionnaire items, to encourage responsiveness to the email request. Because all male participants completed the measures about their relationship status and self-reported love outside of the context of the communication study, and because the most critical data were collected in the context of this study, we believe that this inconsistency in protocol was unlikely to affect results.

The mimicry study was described as a study about how information was communicated in an interview format. Upon arrival to the laboratory, the men were paired with a 21 yearold Caucasian female confederate who was judged to be highly attractive in pretest ratings and informed that they would be participating in a structured interview while being videotaped. The interview task was a shortened version of the Relationship Closeness 
Induction Task (RCIT) (Sedikides et al. 1999). The confederate was "randomly assigned" to the role of interviewer, and she posed 15 questions to the male participants, which escalated from superficial ("What is your major?") to more intimate ("What is your happiest childhood memory?"). To encourage communication and increase comfort levels, the room was furnished with two comfortable chairs, caddy corner to one another at a 90 degree angle, soft lighting, and a beige curtain in the background. The confederate was blind to the relationship status of her interaction partner. To maintain consistency in her behavior, the confederate was instructed to cross her legs in the direction of the participant, a flirtatious nonverbal posture (Koeppel et al. 1993), to act as naturally as possible, and to minimize her responses to participants' comments. So that the confederate's minimal responses would not be perceived as rude, the experimenter instructed the dyad to try to stay as close as possible to the structured interview. During the interview, the confederate touched her face every $15 \mathrm{~s}$ (in different locations) as signaled by a vibrating timer in her pocket. In addition, she touched her hair every time she posed a question-a "flirtatious gesture" (Givens 1978; McCormick and Jones 1989). The number of times that participants touched their heads during the interview served as the primary dependent measure. After the interview, the men completed a post-experimental questionnaire assessing perceptions of the task and perceptions of the confederate (including perceived attractiveness, interest in seeing her again, and attraction to the confederate). Participants were then debriefed and probed for suspicion.

\section{Coding Procedure for Nonverbal Behaviors}

Two independent coders who were blind to relationship status counted the number of times that men touched their heads; first during a minute of baseline in which men were left alone, and then the remainder of the interaction after the experimenter left the room. The interrater reliability for head-touch was strong for both the baseline $(r=.90)$ and for the interview $(r=.96)$, so the two raters' frequencies were averaged at both time periods, and these averages were converted to a rate per minute to control for differences in length of interview.

The research assistants also coded the following behaviors for frequency of occurrence: self-touch on other parts of the body, touching the confederate, nodding, number of separate incidences of forward lean, gestures, smiling, and laughter. Openness of posture was coded separately for the upper and lower parts of the body. Every $30 \mathrm{~s}$, a determination of open or closed posture was made for the upper and lower body. The upper body was described as open if arms were uncrossed and at least one arm was not touching the torso. The lower body was coded as open if legs were uncrossed and knees were not touching. Posture was then calculated as percentage of time during the interaction that the participant displayed an open position. As a result, participants who maintained an open posture at 9 points (at $30 \mathrm{~s}$ intervals) out of 12 would be rated a $75 \%$ for open posture.

Two nonverbal measures were omitted from analyses. "Touching of the confederate" was omitted because only one participant touched the confederate during the entire study, in order to shake her hand at the end of their interaction. Forward lean was also omitted due to poor reliability at baseline $(r=.40)$ and during the interaction $(r=.30)$. Although the baseline reliabilities were generally slightly lower (ranging from .49 for upper body open posture to .94 for gesture) than those during the interaction (ranging from .82 smiling to .996 for lower body open posture), this can be attributed in part to the low frequencies of behaviors occurring during the one-minute baseline period. Because interrater reliabilities for the nonverbal measures were generally strong, the frequencies for the two raters were 
averaged for the baseline and interaction periods and then converted to rates as a function of time.

\section{Procedure for Vocal Samples}

An attempt was made to standardize the topic of conversation for vocal ratings. Responses to the questions "What is your favorite class at UB (University of Baltimore) and why?" were clipped out of all of the interactions because this question tended to consistently produce long responses. In order to ensure that the confederate's vocalics did not interact with dating exclusivity, a sample of the confederate's voice asking the question above was also included in ratings. This yielded 104 segments of speech for ratings (53 segments of the confederate's speech and 51 segments of participants' speech due to the two omissions), so two rating groups were created to reduce rater fatigue. Both rating groups included an equal number of female and male clips, which were randomly assigned to group.

A total of 44 students from the University of Baltimore served as raters in exchange for course credit. After three individuals who did not report a heterosexual orientation were omitted, Group One included 16 people ( 8 men and 8 women) and Group Two included 28 people (14 men and 14 women). Raters were quite diverse in terms of age $(M=24.3$, $S D=10.6$, ranging from 18 to 61 ) and ethnicity (45.5\% African-American, $4.5 \%$ Asian, $31.8 \%$ Caucasian, $9.1 \%$ Hispanic, and $9.1 \%$ reported mixed ethnicities or other).

A male experimenter conducted all of the trials, playing the voice clips in a randomized sequence for raters. Raters completed ratings one at a time in a quiet room. They were instructed to listen to each audio clip and rate the voices on a scale from 1 (not at all pleasant) to 9 (extremely pleasant). Raters were permitted to have the clips repeated if they desired.

\section{Results}

Although ratings of the confederate's attractiveness were very high $(M=7.5$ on a 9 point scale, with $9=$ extremely attractive), two men rated her attractiveness at less than midpoint. Because it was critical that men perceived the confederate to be attractive in order to appropriately test the hypotheses, these two men were omitted from analysis, one from the exclusive daters condition (leaving $n=25$ ) and one from the non-exclusive daters condition (leaving $n=24$ ).

\section{Hypothesis 1}

To test the hypothesis that relationship status would predict men's tendency to mimic an attractive opposite-sex other, we conducted an ANCOVA using dating exclusivity as the predictor variable, baseline head-touching as a covariate, and rate of head touching (as a function of time) as the dependent measure. Contrary to Hypothesis 1, although exclusive daters had lower rates of head-touching $(M=.93, S D=1.01)$ than non-exclusive daters $(M=1.24, S D=1.23)$, results were not significant, $F(1,46)=.97, p=.33$.

For the nonverbal measures, we examined the pattern of correlations in an attempt to simplify the data, but the dependent measures were largely uncorrelated. An exploratory factor analysis confirmed the relative independence of the items. As a result, we conducted separate ANCOVAs on self-touch, nodding, laughing, smiling, upper body open posture, 
lower body open posture, and gesture using dating exclusivity as the predictor variable, and baseline frequency as the covariate. Nonverbal reactions to an attractive confederate were differentiated by dating exclusivity for only one measure, smiling, $F(1,46)=5.34$, $p=.025, \eta^{2}=.10$. Non-exclusive daters had a significantly higher rate of smiling $(M=1.33, S D=.67)$ than did exclusive daters $(M=.96, S D=.48)$.

To test Hypothesis 1 for the vocal ratings, pleasantness ratings were averaged for each voice, and analyses were conducted on these averages. Initial independent samples t-tests revealed significant rater group differences for pleasantness ratings of the confederate and the participants, so this variable was added to the analyses. 2 (group: 1 or 2 ) x 2 (dating exclusivity: exclusive or non-exclusive) ANOVAs were conducted on the pleasantness ratings of the confederate's voice and the participants' voices. Although group 2 rated the confederate's vocal samples as significantly more pleasant-sounding than did group $1, F(1$, $45)=93.15, p<.001, \eta^{2}=.66$, there was no significant main effect for dating exclusivity or interaction with rating group, suggesting that the confederate sounded uniformly pleasant while interacting with exclusive and non-exclusive men. The main effect for group was also significant for participant pleasantness ratings, $F(1,45)=62.02, p<.001$, $\eta^{2}=.55$, with group 2 assigning higher ratings than group 1 , perhaps revealing that the second group was globally more positive in ratings.

Although the overall main effect for dating exclusivity on participant pleasantness ratings was not significant, $F(1,45)=2.60, p=.11$, dating exclusivity did significantly interact with rating group, $F(1,45)=4.49, p=.04, \eta^{2}=.04$. Group 2 assigned similarly high ratings for exclusive and non-exclusive samples $(M=4.77$ and $M=4.68$, respectively), $F(1,23)=.11, p=.74$, but group 1 rated exclusive daters' voices as significantly less pleasant-sounding $(M=2.93, S D=.65)$ than non-exclusive daters' voices $(M=3.61, S D=.50), F(1,22)=8.53, p=.008, \eta^{2}=.28$, providing some support for Hypothesis 1.

\section{Hypothesis 2}

To test the prediction that mimicry would be positively associated with romantic interest, a composite item that averaged perceived attractiveness of the confederate, reported attraction to the confederate, and interest in seeing her again $(\alpha=.86)$ was created. In support of Hypothesis 2, the partial correlation between mimicry and romantic interest (controlling for baseline head-touching behavior) indicated that men with greater romantic interest in the female confederate engaged in significantly more nonconscious mimicry, $r(48)=.31, p=.03$.

An inconsistent relationship between self-reported romantic interest and vocal pleasantness emerged. While the overall correlation between vocal pleasantness and interest did not achieve significance, $r(49)=.11, p=.58$, the correlation between pleasantness and interest approached significance for group $2[r(23)=.37, p=.07]$ but not group 1 $[r(24)=.24, p=.24$.]. None of the other dependent measures were significantly correlated with romantic interest.

\section{Hypothesis 3}

Analyses were conducted on the mean values of the love scale and the passion, commitment, and intimacy subscales to test Hypothesis 3. Despite the small sample size $(d f=25)$, mimicry of an attractive opposite sex other was significantly inversely related to selfreported love $(r=-.44, p=.02)$ and passion $(r=-.42, p=.03)$. Similarly, moderate 
negative correlations were observed between mimicry and commitment $(r=-.35$, $p=.07)$ and mimicry and intimacy $(r=-.33, p=.09)$, although these correlations did not obtain traditional levels of significance. These results offer some support for Hypothesis 3 . No other nonverbal behaviors were significantly associated with love, and the small sample size of exclusive daters prohibited correlational analyses with voice.

\section{Hypothesis 4-Devaluation Hypothesis}

An independent sample $t$ test was used to test the devaluation hypothesis that exclusive daters would evaluate the confederate less favorably than would non-exclusive daters. Consistent with Hypothesis 4, non-exclusive daters expressed significantly more romantic interest in the confederate $(M=7.68, S D=.97)$ than did exclusive daters $(M=6.83$, $S D=1.39), t(47)=2.48, p=.02, d=.71$.

\section{Discussion}

In general, it was theorized that individuals utilize their nonverbal behavior as a nonconscious mechanism to signal availability to others. Specifically, we predicted that individuals in exclusive dating relationships who were exposed to a highly attractive alternative would engage in relationship-protective behavior, and would consequently decrease behaviors that communicate interest, affection, and flirtation. In addition, we predicted that affiliative nonverbal behaviors would be positively correlated with romantic interest in the confederate and negatively correlated with self-reported love for one's romantic partner. Consistent with the devaluation hypothesis, we predicted that exclusive daters would evaluate the attractive confederate less favorably than the non-exclusive daters.

The behaviors that emerged as most predictive of relationship-maintenance processes were mimicry, smiling, and voice. Although the results were supportive of the devaluation hypothesis (Hypothesis 4) (Johnson and Rusbult 1989), in that exclusive daters evaluated the attractive confederate less favorably and reported less romantic interest in her than did non-exclusive daters, there were few differences in nonverbal behavior between the groups. However, non-exclusive daters smiled more than exclusive daters, which is evidence of interest and flirtation (Givens 1978; Koeppel et al. 1993; McCormick and Jones 1989). In addition, although the effects were not uniform, some vocal samples clipped from exclusive daters were rated as significantly less pleasant-sounding than those of nonexclusive daters, and for one group of voices, vocal pleasantness and romantic interest were associated. Because group 1 rated different vocal samples than did group 2, it is difficult to determine whether these results are due to differences in rater sensitivity (Hall and Bernieri 2001) or differences in the vocal samples. Nonetheless, this effect offers some tentative support for the growing body of literature on vocal differences in relational contexts (Farley et al. 2013; Hughes et al. 2010).

The more significant trend in the data relates to the importance of nonconscious mimicry as a social distance mechanism. In support of Hypothesis 2, men who privately expressed romantic interest in the confederate increased mimicry of a confederate's gesture, and likely did so automatically, unintentionally, and outside of conscious awareness (Chartrand and Bargh 1999; Lakin and Chartrand 2003). Mimicry's link with love is potentially more compelling. Exclusive daters modulated their nonverbal behavior in a relationship-protective fashion even though they completed the love measure as part of a 
separate study in a different session, and despite the lack of salience of their relationship status in the current study. Specifically, in keeping with Hypothesis 3, men reporting more overall love and passion for their romantic partners engaged in significantly less mimicry of an attractive alternative, potentially in an effort to distance themselves from a threat to their romantic relationships. This trend was also found for commitment and intimacy, although the effects were not as strong. Participants increased mimicry to communicate interest and decreased mimicry to communicate desired distance; these results convey that individuals implicitly understand mimicry's affiliative function and moderate the tendency to mimic according to their motivational goals.

The relative dearth of support for the nonverbal correlates of attraction was, at first, surprising. Despite how positively participants rated the confederate, few nonverbal cues were displayed that reflected romantic interest in her. One explanation for these findings pertains to the complex role men play in the courtship dance (Grammer et al. 1998). Several researchers have maintained that men are nonverbally "quiet" in the earlier stages of courtship and flirting, waiting until they are more certain of a woman's romantic interest before becoming active in the flirtation process (Givens 1978; McCormick and Jones 1989). Women act as selectors in the early stages of flirtation, attention and recognition (Givens 1978); women who briefly glance toward an interaction partner, then look down, cant their heads to the side, smile frequently, and pout their lips are more likely to be perceived as flirtatious, thus eliciting escalating flirtatious behaviors in men (Givens 1978; McCormick and Jones 1989). In short, although the confederate sat in a flirtatious position, with her legs crossed toward the participant, she did not initiate other flirtatious behaviors during the interaction, which potentially left her male interaction partners uncertain of her intentions. In addition, because the interviews were short sessions (ranging from about 5 to 20.5 min, with $M=8.50, S D=2.37$ ), taking place in a structured experimental session, the academic-oriented goal of achieving experimental credit may have inhibited relational goals. Thus, it could be argued that the cues that did emerge as significant were perhaps more automatic, less controllable, and leakier than other channels (Chartrand and Bargh 1999; Scherer et al. 1985).

This study was not without its limitations. The present study focused exclusively on men and their reactions to an attractive female confederate because of the literature implicating women as "selectors" and initiators of the courtship dance (McCormick and Jones 1989). As a result, further research should be conducted to determine the generalizability of the results for female participants. It is also worthy of mention that Bazzini and Shaffer (1999) argued that devaluation/derogation effects (Johnson and Rusbult 1989) may be explained by enhancement by less committed individuals rather than derogation by more committed individuals. It is true that these competing explanations are difficult to disentangle in the present research, but Lydon et al.'s (2003) study, which carefully pitted enhancement against derogation, found more support for the derogation hypothesis. Another potential limitation was related to design; the current study assessed baseline nonverbal behaviors to approximate a "control condition," but given the subtlety of nonverbal effects, the use of a within subject design with participants interacting with individuals of differing levels of attractiveness might prove more fruitful. Finally, despite the recent trend in the use of a single confederate in mimicry studies (Ashton-James et al. 2007; Cheng and Chartrand 2003; Study 3, Karremans and Verwijmeren 2008), it is possible that the effects obtained in the current study are limited by specific confederate characteristics.

Despite these limitations, the present study is one of the first to assess the degree to which nonverbal behaviors serve relationship-maintenance functions in face-to-face 
interaction with an attractive alternative (See also Karremans and Verwijmeren 2008). We have provided evidence that the same behavior, nonconscious mimicry, was associated with both affiliation goals (to communicate attraction) and relationship-protection goals (to communicate disinterest), thus suggesting that a critical function of nonconscious mimicry is to communicate desired psychological distance. Furthermore, the present research benefitted from a rich dataset, triangulating self-reports for romantic partners, self-reported feelings for the confederate, and 10 nonverbal behaviors. Additionally, there are few empirical articles on flirtation, and this paper speaks to the important role of mimicry in the courtship dance (Grammer et al. 1998). Future research should utilize a more powerful within-subject methodology including both attractive and less attractive confederates and assess the extent to which nonverbal cues serve relationship-maintenance functions for both single and committed individuals.

Acknowledgments I would like to thank Miles Patterson and Betsy Yarrison for their helpful comments on earlier versions of this manuscript and Simone Bolton and Elizabeth Reicks for their dedication to this project. I would also like to thank Dresden Lackey for her work on nonverbal coding and Ryan Bartz for assisting with coding and acting as an experimenter for the voice component of this project.

\section{References}

Agnew, C. R., Van Lange, P. A. M., Rusbult, C. E., \& Langston, C. A. (1998). Cognitive interdependence: Commitment and the mental representation of close relationships. Journal of Personality and Social Psychology, 74(4), 939-954.

Ashton-James, C., Van Baaren, R. B., Chartrand, T. L., Decety, J., \& Karremans, J. (2007). Mimicry and me: The impact of mimicry on self-construal. Social Cognition, 25(4), 518-535. doi:10.1521/soco. 2007.25.4.518.

Bazzini, D. G., \& Shaffer, D. R. (1999). Resisting temptation revisited: Devaluation versus enhancement of an attractive suitor by exclusive and nonexclusive daters. Personality and Social Psychology Bulletin, 25(2), 162-176. doi:10.1177/0146167299025002003.

Bernieri, F. J., \& Rosenthal, R. (1991). Interpersonal coordination: Behavior matching and interactional synchrony. In R. S. Feldman \& B. Rimé (Eds.), Fundamentals of nonverbal behavior (pp. 401-432). New York: Cambridge University Press.

Burgoon, J. K., Guerrero, L. K., \& Floyd, K. (2010). Nonverbal communication. Boston, MA: Allyn \& Bacon.

Chartrand, T. L., \& Bargh, J. A. (1999). The chameleon effect: The perception-behavior link and social interaction. Journal of Personality and Social Psychology, 76(6), 893-910. doi:10.1037/0022-3514.76. $\underline{6.893 .}$

Cheng, C. M., \& Chartrand, T. L. (2003). Self-monitoring without awareness: Using mimicry as a nonconscious affiliation strategy. Journal of Personality and Social Psychology, 85(6), 1170-1179. doi:10. 1037/0022-3514.85.6.1170.

Farley, S. D., Hughes, S. N., \& LaFayette, J. N. (2013). People will know we are in love: Evidence of differences between vocal samples directed toward lovers and friends. Journal of Nonverbal Behavior, 37(3), 123-138. doi:10.1007/s10919-013-0151-3.

Fisher, H. E. (1998). Lust, attraction, and attachment in mammalian reproduction. Human Nature, 9(1), 23-52. doi:10.1007/s12110-998-1010-5.

Floyd, K., \& Burgoon, J. K. (1999). Reacting to nonverbal expressions of liking: A test of interaction adaptation theory. Communication Monographs, 66(3), 219-239. doi:10.1080/03637759909376475.

Giles, H. (2008). Communication accommodation theory. In L. A. Baxter \& D. O. Braithewaite (Eds.), Engaging theories in interpersonal communication: Multiple perspectives (pp. 161-173). Thousand Oaks, CA: Sage Publications Inc.

Givens, D. B. (1978). The nonverbal basis of attraction: Flirtation, courtship, and seduction. Psychiatry: Journal for the Study of Interpersonal Processes, 41(4), 346-359.

Gonzaga, G. C., Haselton, M. G., Smurda, J., Davies, M., \& Poore, J. C. (2008). Love, desire, and the suppression of thoughts of romantic alternatives. Evolution and Human Behavior, 29(2), 119-126. doi:10.1016/j.evolhumbehav.2007.11.003. 
Gonzaga, G. C., Turner, R. A., Keltner, D., Campos, B., \& Altemus, M. (2006). Romantic love and sexual desire in close relationships. Emotion, 6(2), 163-179. doi:10.1037/1528-3542.6.2.163.

Grammer, K., Kruck, K. B., \& Magnusson, M. S. (1998). The courtship dance: Patterns of nonverbal synchronization in opposite-sex encounters. Journal of Nonverbal Behavior, 22(1), 3-29. doi:10.1023/ A:1022986608835.

Gregory, S. W. (1990). Analysis of fundamental frequency reveals covariation in interview partners' speech. Journal of Nonverbal Behavior, 14, 237-251.

Guéguen, N. (2009). Mimicry and seduction: An evaluation in a courtship context. Social Influence, 4(4), 249-255. doi:10.1080/15534510802628173.

Hall, J. A., \& Bernieri, F. J. (Eds.). (2001). Interpersonal sensitivity: Theory and measurement. Mahwah, NJ: Lawrence Erlbaum Associates Publishers.

Hall, J. A., Coats, E. J., \& LeBeau, L. S. (2005). Nonverbal behavior and the vertical dimension of social relations: A meta-analysis. Psychological Bulletin, 131(6), 898-924. doi:10.1037/0033-2909.131.6. 898.

Hatfield, E., \& Rapson, R. L. (1993). Love, sex, and intimacy: Their psychology, biology, and history. New York, NY: HarperCollins College Publishers.

Hughes, S. M., Farley, S. D., \& Rhodes, B. C. (2010). Vocal and physiological changes in response to the physical attractiveness of conversational partners. Journal of Nonverbal Behavior, 34(3), 155-167. doi:10.1007/s10919-010-0087-9.

Johnson, D. J., \& Rusbult, C. E. (1989). Resisting temptation: Devaluation of alternative partners as a means of maintaining commitment in close relationships. Journal of Personality and Social Psychology, 57(6), 967-980. doi:10.1037/0022-3514.57.6.967.

Karremans, J. C., \& Verwijmeren, T. (2008). Mimicking attractive opposite-sex others: The role of romantic relationship status. Personality and Social Psychology Bulletin, 34(7), 939-950. doi:10.1177/ 0146167208316693.

Koeppel, L. B., Montagne-Miller, Y., O’Hair, D., \& Cody, M. J. (1993). Friendly? Flirting? Wrong? In P. J. Kalbfleisch (Ed.), Interpersonal communication: Evolving interpersonal relationships (pp. 13-32). Hillsdale, NJ: Lawrence Erlbaum Associates Inc.

LaFrance, M., \& Ickes, W. (1981). Posture mirroring and interactional involvement: Sex and sex typing effects. Journal of Nonverbal Behavior, 5(3), 139-154. doi:10.1007/BF00986131.

Lakin, J. L., \& Chartrand, T. L. (2003). Using nonconscious behavioral mimicry to create affiliation and rapport. Psychological Science, 14(4), 334-339. doi:10.1111/1467-9280.14481.

Lakin, J. L., Chartrand, T. L., \& Arkin, R. M. (2008). I am too just like you: Nonconscious mimicry as an automatic behavioral response to social exclusion. Psychological Science, 19(8), 816-822. doi:10. 1111/j.1467-9280.2008.02162.x.

Lydon, J. E., Fitzsimons, G. M., \& Naidoo, L. (2003). Devaluation versus enhancement of attractive alternatives: A critical test using the calibration paradigm. Personality and Social Psychology Bulletin, 29(3), 349-359. doi:10.1177/0146167202250202.

Maner, J. K., Rouby, D. A., \& Gonzaga, G. C. (2008). Automatic inattention to attractive alternatives: The evolved psychology of relationship maintenance. Evolution and Human Behavior, 29(5), 343-349. doi:10.1016/j.evolhumbehav.2008.04.003.

McCormick, N. B., \& Jones, A. J. (1989). Gender differences in nonverbal flirtation. Journal of Sex Education \& Therapy, 15(4), 271-282.

McGarva, A. R., \& Warner, R. M. (2003). Attraction and social coordination: Mutual entrainment of vocal activity rhythms. Journal of Psycholinguistic Research, 32(3), 335-354.

Miller, R. S. (1997). Inattentive and contented: Relationship commitment and attention to alternatives. Journal of Personality and Social Psychology, 73(4), 758-766.

Moody, E. J., \& McIntosh, D. N. (2011). Mimicry of dynamic emotional and motor-only stimuli. Social Psychological and Personality Science, 2(6), 679-686. doi:10.1177/1948550611406741.

Murray, S. L., Griffin, D. W., Derrick, J. L., Harris, B., Aloni, M., \& Leder, S. (2011). Tempting fate or inviting happiness? Unrealistic idealization prevents the decline of marital satisfaction. Psychological Science, 22(5), 619-626. doi:10.1177/0956797611403155.

Murray, S. L., Holmes, J. G., \& Griffin, D. W. (1996). The benefits of positive illusions: Idealization and the construction of satisfaction in close relationships. Journal of Personality and Social Psychology, 70(1), 79-98. doi:10.1037//0022-3514.70.1.79.

Natale, M. (1975). Convergence of mean vocal intensity in dyadic communication as a function of social desirability. Journal of Personality and Social Psychology, 32(5), 790-804. doi:10.1037/0022-3514. 32.5.790. 
Patterson, M. L. (2006). The evolution of theories of interactive behavior. In V. Manusov \& M. L. Patterson (Eds.), The Sage handbook of nonverbal communication (pp. 21-39). Thousand Oaks, CA: Sage Publications.

Pipitone, R. N., \& Gallup, G. G. (2008). Women's voice attractiveness varies across the menstrual cycle. Evolution and Human Behavior, 29(4), 268-274. doi:10.1016/j.evolhumbehav.2008.02.001.

Renninger, L. A., Wade, T. J., \& Grammer, K. (2004). Getting that female glance. Evolution and Human Behavior, 25(6), 416-431. doi:10.1016/j.evolhumbehav.2004.08.006.

Rizzolatti, G., \& Craighero, L. (2004). The mirror neuron system. Annual Review of Neuroscience, 27(1), 169-192. doi:10.1146/annurev.neuro.27.070203.144230.

Rosenberg, M. (1965). Society and the adolescent self-image. Princeton, New Jersey: Princeton University Press.

Rubin, Z. (1970). Measurement of romantic love. Journal of Personality and Social Psychology, 16, 265-273.

Scherer, K. R., Feldstein, S., Bond, R. N., \& Rosenthal, R. (1985). Vocal cues to deception: A comparative channel approach. Journal of Psycholinguistic Research, 14(4), 409-425. doi:10.1007/BF01067884.

Sedikides, C., Campbell, W. K., Reeder, G. D., \& Elliot, A. J. (1999). The relationship closeness induction task. Representative Research in Social Psychology, 23, 1-4.

Snyder, M. (1974). Self-monitoring of expressive behavior. Journal of Personality and Social Psychology, 30, 526-537.

Sternberg, R. J. (1986). A triangular theory of love. Psychological Review, 93(2), 119-135. doi:10.1037/ 0033-295X.93.2.119. 